\title{
Group medical visits in the follow-up of women with a $B R C A$ mutation: design of a randomized controlled trial
}

\author{
Annemiek Visser ${ }^{1 *}$, Judith B Prins ${ }^{2}$, Nicoline Hoogerbrugge ${ }^{3}$ and Hanneke WM van Laarhoven ${ }^{1}$
}

\begin{abstract}
Background: $B R C A$ mutation carriers have a $40-80 \%$ life-time risk of developing breast cancer. They may opt for yearly breast cancer surveillance or for prophylactic mastectomy. Both options show increased survival rates. It is a complex choice to be made between these two options. As a result most women experience high levels of distress and high needs for information. To fulfill the needs for psychosocial support and information we have introduced group medical consultations (GMCs). A GMC provides individual medical visits conducted within a group. This 90 minute group-visit with 8-12 patients gives patients the opportunity to spend more time with their clinician and a behavioral health professional and learn from other patients experiencing similar topics. However, it should be noted that group sessions may increase fear in some patients or influence their decision making.
\end{abstract}

Methods/design: In this randomized controlled trial, 160 BRCA mutation carriers diagnosed maximally 2 years ago are recruited from the Radboud University Nijmegen Medical Centre. Participants are randomized in a 1:1 ratio to either the GMC intervention group (onetime participation in a GMC instead of a standard individual visit) or to a usual care control group. Primary outcome measures are empowerment and psychological distress (SCL 90). Secondary outcome measures are fear of cancer, information needs before the consultation and the received information, self-examination of the breasts, patient satisfaction, quality of life and cost-effectiveness. Data are collected via self-reported questionnaires 1 week before the visit, and at 1 week and at 3 months follow-up. A pilot study was conducted to test all procedures and questionnaires.

Discussion: The possibility for interaction with other BRCA mutation carriers within a medical visit is unique. This study will assess the effectiveness of GMCs for BRCA mutation carriers to improve empowerment and decrease distress compared to individual visits. If GMCs prove to be effective and efficient, implementation of GMCs in regular care for BRCA mutation carriers will be recommended.

Trial registration: The study is registered at ClinicalTrials.gov (NCT01329068)

\section{Background}

$B R C A$ mutation carriers have a high life-time risk of developing breast cancer and also of ovarian cancer. In a large meta-analysis of ten studies the mean cumulative breast cancer risk at 70 years was $46-80 \%$ for $B R C A 1$ mutation carriers and $40-80 \%$ for $B R C A 2$ mutation carriers [1-3]. Because of this high risk of breast cancer, women with a mutation in either the BRCA1 or BRCA2 gene are offered breast cancer surveillance, which includes annual clinical

\footnotetext{
* Correspondence: A.Visser@onco.umcn.nl

'Department of Medical Oncology, Radboud University Nijmegen Medical Centre, Nijmegen, The Netherlands

Full list of author information is available at the end of the article
}

breast examination, annual mammography and annual contrast enhanced magnetic resonance imaging (MRI) of the breast [4-6]. Alternatively, women may opt for prophylactic bilateral mastectomy with or without breast reconstruction [7-10]. Prophylactic bilateral mastectomy reduces the risk for breast cancer by $89.5-100 \%[11]$, making yearly surveillance unnecessary. Although prophylactic mastectomy minimizes the risk of breast cancer, comparable survival rates are seen for prophylactic mastectomy and yearly breast cancer surveillance [10].

$B R C A$ mutation carriers who underwent treatment for breast cancer before, have to deal with a 50-64\% lifetime risk for developing a second primary breast cancer [12].

\section{Biomed Central}


Most studies among $B R C A$ mutation carriers who had breast cancer have shown a reduction in the risk of contralateral breast cancer, while results on survival rates were diverse [10,13-15]. Besides, the decision for contralateral prophylactic mastectomy depends on age, type of initial breast cancer surgery, prophylactic oophorectomy and the patient's opinion [16].

Thus, $B R C A$ mutation carriers face a complex choice between these options. The knowledge of BRCA carriership and the consequently increased risk of developing breast (and ovarian) cancer may have a large psychosocial impact on mutation carriers. The level of cancer related distress among Jewish women increased significantly after the diagnosis of a $B R C A$ mutation [17]. In another study 36 percent of women diagnosed with a $B R C A 1$ mutation appeared to be sad or crying [18]. Several studies in the Netherlands showed that genetic testing, regardless of the test results may already increase levels of distress $[19,20]$.

The provision of psychosocial support is intrinsically connected to the provision of guidance in the choice between surveillance and a prophylactic mastectomy. In a study of 233 women who were awaiting their initial appointments for risk assessment, consideration of prophylactic mastectomy strongly correlated with high levels of breast cancer anxiety and overestimation of one's breast cancer risk, whereas there was no association with objective breast cancer risk [21]. Recently, it was suggested that standard visit with a psychologist for high-risk women considering prophylactic mastectomy may be indicated since anxiety is one of the main reasons for considering a prophylactic mastectomy, and depression and grief were present in a third of the participating women [22]. Interestingly, in this study uncertainty about surgery and the need for further information were the reasons given most frequently for postponing prophylactic mastectomy, indicating that there is a great need for information in this group [23]. Generally, the decision about surveillance or prophylactic mastectomy is not a medically urgent one and women can indeed take time to gather and process all information and talk about it with others. Of note, patient satisfaction is an important predictor of quality of life, treatment compliance and lower rates of anxiety and depression [24]. In previous studies it has been shown that in order to improve the patient satisfaction it is important for the clinician to discuss psychosocial factors and to be responsive to the patients concerns $[25,26]$.

To fulfill the needs just mentioned concerning psychosocial support and information we have introduced group medical consultations (GMCs) for the surveillance of BRCA mutation carriers. A GMC provides individual medical visits conducted within a group, giving patients the opportunity to spend more time with their own clinician in the setting of a support group with a behavioral health professional and learn from other patients experiencing similar topics. In contrast to the typical 15-20minute office visit, a 90-minute group-visit with 8-12 patients permits ample time for discussion and education. The incorporation of the individual medical visit in a GMC distinguishes GMCs from educational workshops and support- and self-management groups. In general, the group of patients in a GMC is composed of different participants from meeting to meeting. Currently, GMCs have been offered to patients of different ages with a variety of diseases [27,28]. Although several benefits of GMCs compared to individual visits have been reported, the effects have not been evaluated for the surveillance of $B R C A$ mutation carriers.

Most previous studies showed improved satisfaction in patients receiving GMCs and in health professionals providing GMCs. The unhurriedness of the clinician and the time spent with the clinician is appreciated most by patients [29-33]. Clinicians were positive about the innovative and multidisciplinary working method [34]. Besides improved quality of life, which is reported in several studies $[32,35,36]$, also improved health behavior, self-efficacy for following certain health promoting interventions and knowledge of the disease was shown among diabetes patients and patients with coronary artery disease who participated in a group visit $[35,37]$. Also, quality of care is improved. For example, in a study of diabetic patients group visit participation was positively associated with patients receiving preventive procedures, review of medication and microalbuminuria test recorded in the registry [38]. Other studies in diabetic patients have confirmed these results [31,39-41]. When planned carefully, this type of visits may increase clinician satisfaction and productivity [30,36,42-44].

However, it should be noted that group sessions may not be beneficial [45]. Recently the effects of educationalsupport groups for $B R C A$ mutation carriers have been studied [46]. This program included eight sessions with alternately a psychosocial (5 sessions) and a medical information focus (3 sessions); no individual visits were provided in the group. The study provided presumptive evidence that educational-support group participants were more inclined to undergo prophylactic mastectomy than non-participants. Possibly the occurrence of group members getting cancer during surveillance affected other group members. Group participation may have triggered feelings of anticipated regret, i.e. regret that women think they would have if they were to be diagnosed with breast cancer after not (yet) having chosen the option of prophylactic mastectomy [47]. Therefore, before introducing GMCs in regular patient care for $B R C A$ mutation carriers the pros and cons of GMCs for this population should carefully be evaluated. 


\section{Methods/Design \\ Design}

The study examines the effect of GMCs on patient empowerment and psychological distress of $B R C A$ mutation carriers as well as several secondary outcome measures. This randomized controlled trial (RCT) will compare two groups; the intervention group, who will participate in a GMC once and the control group, who will receive care as usual (surveillance in an individual visit).

\section{Ethical consideration}

The study has been approved by the medical ethical committee of the Radboud University Nijmegen Medical Centre. Full medical ethical approval has been obtained in February 2011.

\section{Study sample}

A total of 160 recently diagnosed $B R C A$ mutation carriers will be invited to participate in the study. To stimulate interaction and discussion within the group it is important to compose heterogeneous groups. Nevertheless, some homogeneity is needed to keep the GMCs relevant for everyone [34]. Therefore the following inand exclusion criteria were formulated. Inclusion criteria are: carrier of a $B R C A 1$ or a $B R C A 2$ mutation; diagnosed maximally 2 years ago; and a minimum age of 25 . Exclusion criteria are: currently involved in a diagnostic work-up because of a suspicion of breast cancer, either primary or metastatic; a history of prophylactic mastectomy or current psychiatric disease precluding visits in a group; insufficient command of the Dutch language to be able to follow a group discussion and fill out questionnaires in Dutch.

\section{Recruitment and randomization}

Women with the $B R C A$ mutation having their yearly surveillance in the Radboud University Nijmegen Medical Centre will be informed about the study during an individual visit to the outpatient clinic or approached via a telephone call by the researcher. As shown in Figure 1 patients will be randomized for their next visit

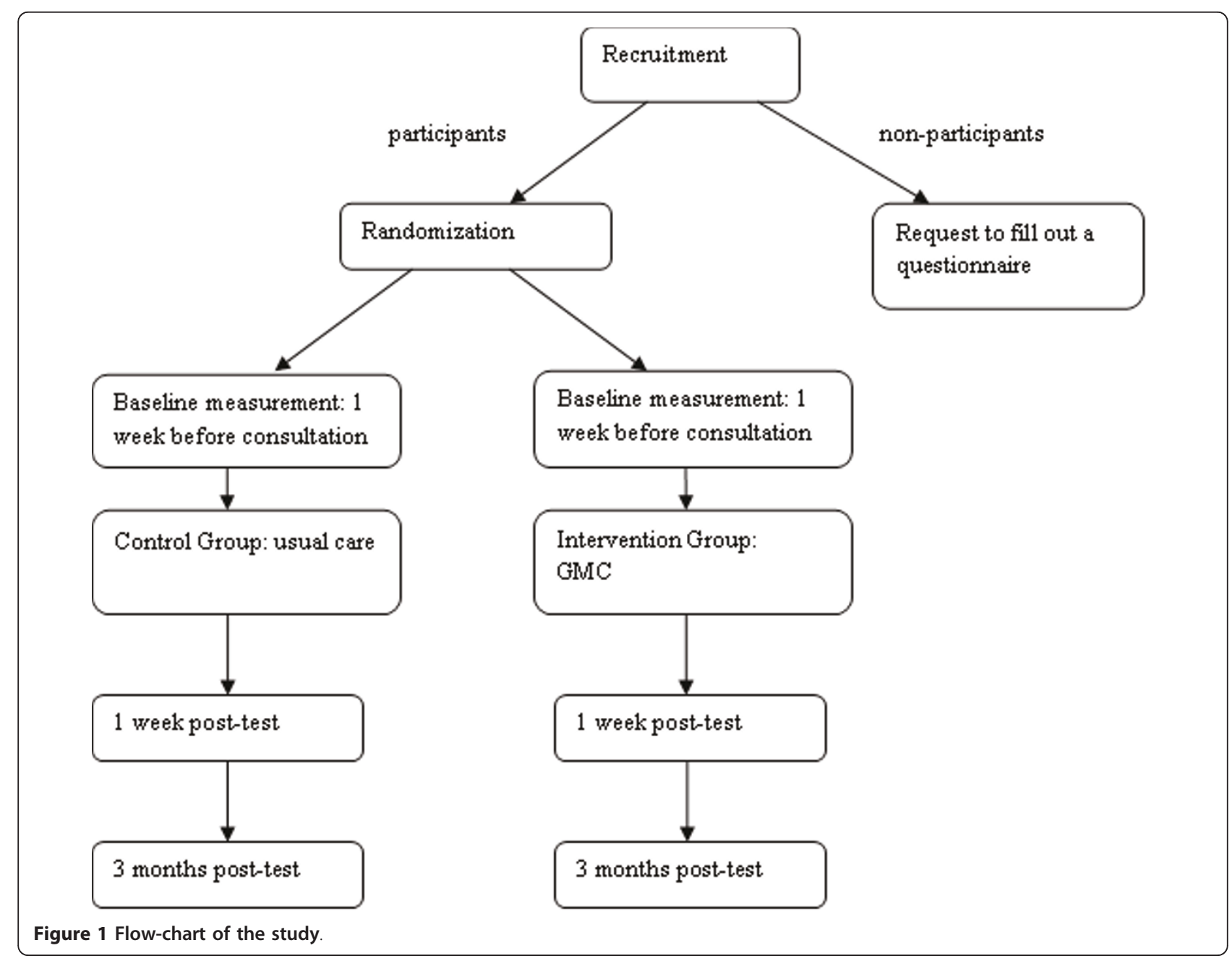


to either the intervention group (GMC) or the control group (individual visit) after informed consent is obtained. Randomization will take place per patient in a 1:1 ration and in blocks of 16 patients. The individual clinician, will meet the same number of patients in a GMC and in an individual consultation, therefore we pre-stratified for clinician.

\section{Intervention}

Patients randomized to the intervention group will participate once in a GMC instead of a standard individual visit. The GMC will provide individual medical visits conducted within a group, giving patients the opportunity to spend more time with their own clinician in the setting of a support group. In this way patients can learn from other patient's experiences with similar topics. A social worker will be present during every GMC. Besides leading the discussion and making sure every patient receives equal attention from the clinician, the social worker will be available for psychosocial related questions and support. The group visit itself will take 90 minutes. In advance, half an hour will be scheduled for physical examination, where privacy concerns will be taken into account. The control group will have their usual individual visit with the clinician. The clinician and the social worker will both use protocols with information based on most up-to-date publications concerning BRCA gene mutation related topics, specially developed for the GMCs.

\section{Study outcomes}

At baseline, 1 week after and 3 months after the (group or individual) visit participants will be asked to fill out a questionnaire. Patients refusing participation will be asked to fill out one questionnaire to gain insight in reasons for not participating. Demographical data will be collected as well as the following measures.

\section{Primary outcome measures}

Empowerment is the first primary outcome, which will be measured using the Empowerment Questionnaire for breast cancer patients. This questionnaire has been developed and validated in the Netherlands for the assessment of empowerment in psychiatric patients. With minor revisions, the 40 -item questionnaire was validated in breast cancer survivors. The study involved 140 non-metastatic breast cancer patients who were treated in the past with curative intent. Four factors were extracted, explaining 53 percent of the total variance. Factor 1 was labeled 'Personal Strength', factor 2 'Social support', factor 3 'Community' and at least factor 4 'Health Care'. The internal consistency reliability for each factor demonstrated good reliability for all four factors and for the total empowerment scale (alpha $=.94)$ [48].
Another primary outcome is psychological distress measured by the Symptom Checklist-90 (SCL-90). SCL90 is designed to evaluate a broad range of psychological problems and symptoms of psychopathology. It can be used for measuring the progress and outcome of psychiatric and psychological treatments [45,49]. It consists of 90 items, yielding nine scores along primary symptom dimensions and three scores among global distress indices. A countless number of studies demonstrated the reliability, validity and utility of the instrument.

\section{Secondary outcome measures}

Besides the primary outcomes, the following secondary outcomes are measured. The Cancer Worry Scale will be used to assess the fear of cancer. It consists of 8 items and is used in several studies among cancer patients. The internal consistency is good (alpha $=.80)$ $[50,51]$.

The information needs before the consultation and the actually received information after the consultation will be measured by a list of relevant topics for BRCA mutation carriers, including topics like prophylactic mastectomy, use of oral contraceptives, depressed mood. Participants can also add their own topics. In advance of the visit participant are asked to fill out which topics they want to discuss during the consultation. One week after the visit participants will indicate on the topic list which topics have actually been discussed.

Self-examination of the breasts will be measured by a question about the frequency of self-examination and about the reason not to examine their own breasts. One question is included to assess the patient's choice for a prophylactic mastectomy or surveillance.

To assess the patient satisfaction a combination of the QUOTE questionnaire [52] and some GMC specific questions will be used [34]. Overall satisfaction with the visit will be rated on a scale from 1 (not satisfied at all) to 5 (very satisfied).

The quality of life will be measured by the EORTCQ30 and the EORTC-BR23. The EORTC-Q30 is a health-related quality of life questionnaire which is validated for oncological clinical research [53]. Chronbach's alpha was close to or higher than 0.70 for seven of the nine scales and ranged between 0.19-0.92 [54]. The questionnaire consists of 30 items, including a functional, symptom and health-related quality of life subscale. The EORTC-BR23 is a validated breast cancer-specific questionnaire $[55,56]$. The questionnaire consists of 23 items, including side effects of therapy, body image, sexuality and outlook for the future.

To evaluate the cost-effectiveness of the intervention costs will be measured by several questions from the Trimbos/iMTA questionnaire for Costs associated with Psychiatric Illness (TiC-P). This is a frequently used 
instrument for economic evaluations in mental health care [57].

The researcher will be present during the GMC for measuring the time spend per patient. This measure will be used in the analyses to test the relation between time spend per patient and the effectiveness of the GMC. Besides, topics discussed during the visits will be measured by the researcher.

\section{Power calculations}

The primary aim of GMCs is to increase patient empowerment and to prevent an increase of psychological distress. Data on these outcome measures for $B R C A$ mutation carriers are not yet available, therefore data from a rather comparable population, breast cancer patients, is used for the power analysis. Also, data of the SCL-90 is more widespread compared to empowerment data for breast cancer patients, therefore results of this questionnaire have been used. A healthy score on the SCL-90 ranges between 90130 , while breast cancer patients, one year or longer after curative treatment for breast cancer, achieved an average score of 138.5 [58]. In this study we strive for a high normal average score of 125 . This implies that an average difference of 13.5 points can be defined as clinically relevant. The standard deviation is 45 , which is based on three norm groups [49]. To assess a clinically relevant effect of GMC on psychological distress with a power of $80 \%$, a two-side significance of 5\%, a standard deviation of 45 and an expected drop-out of $15 \%, 80$ patients need to be included in each group.

\section{Statistical analysis}

For the primary analysis a covariance analysis (ANCOVA) will be conducted. Differences in empowerment and SCL-90 scores (primary outcome measures) at baseline and one week after the GMC between the intervention group and control group will be compared. In addition ANCOVA provides the opportunity to compare trends over time between the two groups. The SCL-90 scores at T1 or T2 will be included as dependent variables and the group (individual consult or GMC) as independent variable. Furthermore, the SCL90 score at baseline will be a covariate. The analysis of the secondary outcome measures is a repeated measurement analysis (ANOVA or mixed model) to compare trends over time between the two groups.

\section{Cost-effectiveness analyses}

Beside effectiveness of the intervention, another important measure is the cost-effectiveness. This study will compare the difference in total costs for health care and production losses between the intervention group and the control group. These costs will be estimated by several questions. The total direct medical costs (for example outpatient visits, length of stay in hospital, use of medication) will be calculated by the use of reference unit prices of health care services. The total estimated costs are rated against change in the level of distress.

\section{Preliminary results}

Seven BRCA mutation carriers participated in a GMC in our pilot study. The overall patient satisfaction with the GMC was quite promising with an average score of 3.7 $(\mathrm{sd}=1.1)$ on a range of $1-5$. More than half of the participants $(57.1 \%)$ would choose a GMC in the future again. $42.9 \%$ experienced support from other patients. A comparison of the topics, which are discussed during the GMC according to patients and according to health professionals showed that according to patients fewer topics were discussed in the GMC compared to the number of topics that health care workers reported (table 1). For instance, all care providers indicated that the risk for breast cancer and the results of the MRI and mammography were discussed, while less than half of the patients mentioned these topics.

\section{Discussion}

Several studies showed the advantages of GMCs compared to individual visits. However, for $B R C A$ mutation carriers the effectiveness has never been studied. Since GMCs may have disadvantages the effects of GMCs should carefully be studied.

Most research among other patient groups showed positive effects on patient and caregiver's satisfaction. The participants in the pilot study were also satisfied about the GMC. This is of importance as a high patient satisfaction is related to a high quality of life, more compliance and less anxiety and depression [24].

We observed a remarkable difference in the number of topics discussed during the GMC according to patients and according to health care workers. This may be explained by the fact that patients remember only 20-60\% of the information in medical visits and only remember information that is relevant to them at that moment. The working memory is limited, therefore only relevant information will be processed and stored [59]. It should be noted that $B R C A$ mutation carriers have a large need for information [22].

GMCs give the opportunity to provide this information in a relatively short amount of time, while patients can make a selection of information, which is particularly relevant for their own situation. Besides, we expect information gathered from fellow patients to be better remembered. At the same time any incorrect information given by other patients can be corrected immediately by the health care professional to prevent misunderstandings.

GMCs may fulfill the need for extra attention for psychosocial related problems, both by health care 
Table 1 Topics discussed during GMC according to patients and to health care professionals

\begin{tabular}{|c|c|c|}
\hline Topics & $\begin{array}{l}\text { Care professionals } \\
(\%)(n=2)\end{array}$ & $\begin{array}{l}\text { Patients } \\
(\%)(n=7)\end{array}$ \\
\hline The risk of breast cancer & 100 & 42.9 \\
\hline Self-examination of the breasts & 100 & 100 \\
\hline Results from MRI and mammography & 100 & 28.6 \\
\hline Control frequency in the hospital & 100 & 71.4 \\
\hline Prophylactic mastectomy & 100 & 57.1 \\
\hline Factors influencing the choice between prophylactic mastectomy or surveillance & 100 & 57.1 \\
\hline Breast reconstruction & 0 & 28.6 \\
\hline Breast enlargement & 0 & 0 \\
\hline Controls of ovaries & 0 & 0 \\
\hline Surgical removal of the ovaries & 100 & 57.1 \\
\hline Use of birth control pills & 0 & 0 \\
\hline Pregnancy & 100 & 71.4 \\
\hline Breast feeding & 100 & 71.4 \\
\hline Osteoporosis & 0 & 14.3 \\
\hline Hot flashes & 50 & 28.6 \\
\hline Situation of family members & 100 & 100 \\
\hline Reaction of partner/family/friends on the diagnosis & 0 & 28.6 \\
\hline Sad feelings & 100 & 71.4 \\
\hline Feelings of fear & 100 & 85.7 \\
\hline Contact with social work & 0 & 14.3 \\
\hline Other topics & 50 & 28.6 \\
\hline
\end{tabular}

providers and by fellow patients. The possibility for interaction with other $B R C A$ mutation carriers within a medical visit is unique.

Of note, despite the widespread implementation of GMCs in different patient groups, the cost-effectiveness remains unproven. In the current health care system cost effectiveness is an important factor to take into account too.

In conclusion, the aim of our study is to assess the effectiveness of GMCs for BRCA mutation carriers to improve empowerment and decrease distress compared to individual visits. If GMCs prove to be effective and efficient, implementation of GMCs in regular care for $B R C A$ mutation carriers will be recommended.

\section{Acknowledgements and Funding}

The study is funded by the Pink Ribbon Foundation from the Netherlands.

\section{Author details}

'Department of Medical Oncology, Radboud University Nijmegen Medical Centre, Nijmegen, The Netherlands. '2Department of Medical Psychology, Radboud University Nijmegen Medical Centre, Nijmegen, The Netherlands. ${ }^{3}$ Department of Human Genetics, Radboud University Nijmegen Medical Centre, Nijmegen, The Netherlands.

\section{Authors' contributions}

$\mathrm{JBP}$ and $\mathrm{NH}$ have contributed to the study protocol and revised the manuscript. HWML has also contributed to the study protocol, conducted the pilot study, performed analysis of the pilot data, and revised the manuscript. AV has contributed to the study protocol, performed analysis of the pilot data and wrote the manuscript. All authors read and approved the final manuscript.

\section{Competing interests}

The authors declare that they have no competing interests.

Received: 10 June 2011 Accepted: 24 August 2011

Published: 24 August 2011

\section{References}

1. Chen S, Parmigiani G: Meta-analysis of BRCA1 and BRCA2 penetrance. J Clin Oncol 2007, 25(11):1329-1333.

2. Antoniou A, Pharoah PD, Narod S, Risch HA, Eyfjord JE, Hopper JL, Loman N, Olsson H, Johannsson O, Borg A, Pasini B, Radice P, Manoukian S, Eccles DM, Tang N, Olah E, Anton-Culver H, Warner E, Lubinski J, Gronwald J, Gorski B, Tulinius H, Thorlacius S, Eerola H, Nevanlinna H, Syrjakoski K, Kallioniemi OP, Thompson D, Evans C, Peto J, Lalloo F, Evans DG, Easton DF: Average risks of breast and ovarian cancer associated with BRCA1 or BRCA2 mutations detected in case Series unselected for family history: a combined analysis of 22 studies. American journal of human genetics 2003, 72(5):1117-1130.

3. King MC, Marks JH, Mandell JB: Breast and ovarian cancer risks due to inherited mutations in BRCA1 and BRCA2. Science (New York, NY 2003, 302(5645):643-646.

4. Warner E, Plewes DB, Hill KA, Causer PA, Zubovits JT, Jong RA, Cutrara MR, DeBoer G, Yaffe MJ, Messner SJ, Meschino WS, Piron CA, Narod SA: Surveillance of BRCA1 and BRCA2 mutation carriers with magnetic resonance imaging, ultrasound, mammography, and clinical breast examination. Jama 2004, 292(11):1317-1325.

5. Kriege M, Brekelmans $C T$, Boetes $C$, Besnard PE, Zonderland HM Obdeijn IM, Manoliu RA, Kok T, Peterse H, Tilanus-Linthorst MM, Muller SH, Meijer S, Oosterwijk JC, Beex LV, Tollenaar RA, de Koning HJ, Rutgers EJ, Klijn JG: Efficacy of MRI and mammography for breast-cancer screening in women with a familial or genetic predisposition. The New England journal of medicine 2004, 351(5):427-437.

6. Rijnsburger AJ, van Oortmarssen GJ, Boer R, Draisma G, To T, Miller AB, de Koning HJ: Mammography benefit in the Canadian National Breast Screening Study-2: a model evaluation. International journal of cancer 2004, 110(5):756-762.

7. Meijers-Heijboer H, van Geel B, van Putten WL, Henzen-Logmans SC, Seynaeve C, Menke-Pluymers MB, Bartels CC, Verhoog LC, van den 
Ouweland AM, Niermeijer MF, Brekelmans CT, Klijn JG: Breast cancer after prophylactic bilateral mastectomy in women with a BRCA1 or BRCA2 mutation. The New England journal of medicine 2001, 345(3):159-164.

8. Rebbeck TR, Friebel T, Lynch HT, Neuhausen SL, van 't Veer L, Garber JE, Evans GR, Narod SA, Isaacs C, Matloff E, Daly MB, Olopade OI, Weber BL: Bilateral prophylactic mastectomy reduces breast cancer risk in BRCA1 and BRCA2 mutation carriers: the PROSE Study Group. J Clin Oncol 2004, 22(6):1055-1062.

9. Kaas R, Verhoef $S$, Wesseling J, Rookus MA, Oldenburg HS, Peeters MJ, Rutgers EJ: Prophylactic mastectomy in BRCA1 and BRCA2 mutation carriers: very low risk for subsequent breast cancer. Annals of surgery 2010, 251(3):488-492.

10. Kurian AW, Sigal BM, Plevritis SK: Survival analysis of cancer risk reduction strategies for BRCA1/2 mutation carriers. J Clin Oncol 2010, 28(2):222-231.

11. Calderon-Margalit R, Paltiel O: Prevention of breast cancer in women who carry BRCA1 or BRCA2 mutations: a critical review of the literature. International journal of cancer 2004, 112(3):357-364.

12. Metcalfe K, Lynch HT, Ghadirian P, Tung N, Olivotto I, Warner E, Olopade Ol, Eisen A, Weber B, McLennan J, Sun P, Foulkes WD, Narod SA: Contralateral breast cancer in BRCA1 and BRCA2 mutation carriers. J Clin Oncol 2004, 22(12):2328-2335.

13. van Sprundel TC, Schmidt MK, Rookus MA, Brohet R, van Asperen CJ, Rutgers EJ, Van't Veer LJ, Tollenaar RA: Risk reduction of contralateral breast cancer and survival after contralateral prophylactic mastectomy in BRCA1 or BRCA2 mutation carriers. British journal of cancer 2005, 93(3):287-292.

14. Menke-Pluymers MB, Seynaeve C, van Geel AN, Klijn JG, Meijers-Heijboer EJ, Eggermont AM: Preventief chirugisch ingrijpen bij erfelijke belasting voor borstkanker. Ned Tijdschr Geneeskd 2005, 149:2663-2667.

15. Herrinton $L$, Barlow WE, Yu O, Geiger AM, Elmore JG, Barton MB, Harris EL, Rolnick S, Pardee R, Husson G, Macedo A, Fletcher SW: Efficacy of prophylactic mastectomy in women with unilateral breast cancer: a cancer research network project. J Clin Oncol 2005, 23(19):4275-4286.

16. Metcalfe KA, Lubinski J, Ghadirian P, Lynch H, Kim-Sing C, Friedman E, Foulkes WD, Domchek S, Ainsworth P, Isaacs C, Tung N, Gronwald J, Cummings S, Wagner T, Manoukian S, Moller P, Weitzel J, Sun P, Narod SA: Predictors of contralateral prophylactic mastectomy in women with a BRCA1 or BRCA2 mutation: the Hereditary Breast Cancer Clinical Study Group. J Clin Oncol 2008, 26(7):1093-1097.

17. Metcalfe KA, Poll A, Llacuachaqui M, Nanda S, Tulman A, Mian N, Sun P, Narod SA: Patient satisfaction and cancer-related distress among unselected Jewish women undergoing genetic testing for BRCA1 and BRCA2. Clinical genetics 2010, 78(5):411-417.

18. Lynch HT, Lemon SJ, Durham C, Tinley ST, Connolly C, Lynch JF, Surdam J, Orinion E, Slominski-Caster S, Watson P, Lerman C, Tonin P, Lenoir G, Serova O, Narod S: A descriptive study of BRCA1 testing and reactions to disclosure of test results. Cancer 1997, 79(11):2219-2228.

19. van Dijk S, Timmermans DR, Meijers-Heijboer $H$, Tibben A, van Asperen CJ, Otten W: Clinical characteristics affect the impact of an uninformative DNA test result: the course of worry and distress experienced by women who apply for genetic testing for breast cancer. J Clin Oncol 2006, 24(22):3672-3677.

20. van Oostrom I, Meijers-Heijboer $H$, Lodder LN, Duivenvoorden HJ, van Gool AR, Seynaeve C, van der Meer CA, Klijn JG, van Geel BN, Burger CW, Wladimiroff JW, Tibben A: Long-term psychological impact of carrying a BRCA1/2 mutation and prophylactic surgery: a 5-year follow-up study. J Clin Oncol 2003, 21(20):3867-3874.

21. Meiser B, Butow P, Friedlander M, Schnieden V, Gattas M, Kirk J, Suthers G, Haan E, Tucker K: Intention to undergo prophylactic bilateral mastectomy in women at increased risk of developing hereditary breast cancer. J Clin Oncol 2000, 18(11):2250-2257.

22. Tan MB, Bleiker EM, Menke-Pluymers MB, Van Gool AR, van Dooren S, Van Geel BN, Tilanus-Linthorst MM, Bartels KC, Klijn JG, Brekelmans CT, Seynaeve C: Standard psychological consultations and follow up for women at increased risk of hereditary breast cancer considering prophylactic mastectomy. Hereditary cancer in clinical practice 2009, 7(1):6..

23. Landsbergen KM, Brunner HG, Manders P, Hoogerbrugge N, Prins JB: Educational-support groups for BRCA mutation carriers satisfy need for information but do not affect emotional distress. Genetic counseling (Geneva, Switzerland) 2010, 21(4):423-437.
24. Haddad S, Potvin L, Roberge D, Pineault R, Remondin M: Patient perception of quality following a visit to a doctor in a primary care unit. Family practice 2000, 17(1):21-29.

25. Walker MS, Ristvedt SL, Haughey BH: Patient care in multidisciplinary cancer clinics: does attention to psychosocial needs predict patient satisfaction? Psycho-oncology 2003, 12(3):291-300.

26. Uitterhoeve $R$, Bensing J, Dilven E, Donders $R$, deMulder $P$, van Achterberg T: Nurse-patient communication in cancer care: does responding to patient's cues predict patient satisfaction with communication. Psycho-oncology 2009, 18(10):1060-1068.

27. Jaber R, Braksmajer A, Trilling JS: Group visits: a qualitative review of current research. J Am Board Fam Med 2006, 19(3):276-290.

28. Zantinge EM, Seesing FM, Tol FE, Raats CJ, Spreeuwenberg PM, van Dulmen AM: Shared Medical Appointments: experiences of patients and care givers. Nederlands tijdschrift voor geneeskunde 2009, 153:A828.

29. Meehan KR, Hill JM, Root L, Kimtis E, Patchett L, Noffsinger EB: Group medical appointments: organization and implementation in the bone marrow transplantation clinic. Supportive cancer therapy 2006, 3(2):84-90.

30. Beck A, Scott J, Williams P, Robertson B, Jackson D, Gade G, Cowan P: A randomized trial of group outpatient visits for chronically ill older HMO members: the Cooperative Health Care Clinic. Journal of the American Geriatrics Society 1997, 45(5):543-549.

31. Sadur CN, Moline N, Costa M, Michalik D, Mendlowitz D, Roller S, Watson R, Swain BE, Selby JV, Javorski WC: Diabetes management in a health maintenance organization. Efficacy of care management using cluster visits. Diabetes care 1999, 22(12):2011-2017.

32. Scott JC, Conner DA, Venohr I, Gade G, McKenzie M, Kramer AM, Bryant L, Beck A: Effectiveness of a group outpatient visit model for chronically ill older health maintenance organization members: a 2-year randomized trial of the cooperative health care clinic. Journal of the American Geriatrics Society 2004, 52(9):1463-1470.

33. Noffsinger EB, Atkins TN: Assessing a group medical appointment program: a case study at Sutter Medical Foundation. Group Pract J 2001, 48:42-49.

34. Seesing FM, Raats I: Gezamenlijk Medisch Consult. Een praktische handleiding. Houten: Bohn Stafleu; 2009.

35. Trento M, Passera P, Bajardi M, Tomalino M, Grassi G, Borgo E, Donnola C, Cavallo F, Bondonio P, Porta M: Lifestyle intervention by group care prevents deterioration of Type II diabetes: a 4-year randomized controlled clinical trial. Diabetologia 2002, 45(9):1231-1239.

36. Blumenfeld A, Tischio M: Center of excellence for headache care: group model at Kaiser Permanente. Headache 2003, 43(5):431-440.

37. Yehle KS, Sands LP, Rhynders PA, Newton GD: The effect of shared medical visits on knowledge and self-care in patients with heart failure: a pilot study. Heart Lung 2009, 38(1):25-33.

38. Wagner EH, Grothaus LC, Sandhu N, Galvin MS, McGregor M, Artz K, Coleman EA: Chronic care clinics for diabetes in primary care: a systemwide randomized trial. Diabetes care 2001, 24(4):695-700.

39. Clancy DE, Brown SB, Magruder KM, Huang P: Group visits in medically and economically disadvantaged patients with type 2 diabetes and their relationships to clinical outcomes. Topics in health information management 2003, 24(1):8-14.

40. Clancy DE, Cope DW, Magruder KM, Huang P, Salter KH, Fields AW: Evaluating group visits in an uninsured or inadequately insured patient population with uncontrolled type 2 diabetes. The Diabetes educator 2003, 29(2):292-302.

41. Clancy DE, Cope DW, Magruder KM, Huang P, Wolfman TE: Evaluating concordance to American Diabetes Association standards of care for type 2 diabetes through group visits in an uninsured or inadequately insured patient population. Diabetes care 2003, 26(7):2032-2036.

42. Noffsinger EB, Scott J: Practical tips for establishing successful group vist programs. Group Pract J 2000, 49:24-37.

43. Noffsinger EB: Will Drop-In Group Medical Appointments (DIGMAs) Work in Practice? The permanente Journal 1999, 3:58-67.

44. Bronson DL, Maxwell RA: Shared medical appointments: increasing patient access without increasing physician hours. Cleveland Clinic journal of medicine 2004, 71(5):369-370, 372, 374 passim.

45. Prins JB, Bleijenberg G, Bazelmans E, Elving LD, de Boo TM, Severens JL, van der Wilt GJ, Spinhoven P, van der Meer JW: Cognitive behaviour therapy for chronic fatigue syndrome: a multicentre randomised controlled trial. Lancet 2001, 357(9259):841-847. 
46. Landsbergen KM, Prins JB, Kamm YJ, Brunner HG, Hoogerbrugge N: Female BRCA mutation carriers with a preference for prophylactic mastectomy are more likely to participate an educational-support group and to proceed with the preferred intervention within 2 years. Familial cancer 2010, 9(2):213-220.

47. van Dijk S, van Roosmalen MS, Otten W, Stalmeier PF: Decision making regarding prophylactic mastectomy: stability of preferences and the impact of anticipated feelings of regret. J Clin Oncol 2008, 26(14):2358-2363.

48. van de Berg S, Gielissen MF, Prins JB: Validation of an empowerment questionnaire in breast cancer survivors. 12th World Congress of PsychoOncology 2010.

49. Arrindell WA, Ettema JHM: Symptom Checklist-90; Handleiding bij een multidimensionele psychopathologie-indicator. Lisse: Swets \& Zeitlinger B. $V_{i} 2003$.

50. Lerman C, Daly M, Masny A, Balshem A: Attitudes about genetic testing for breast-ovarian cancer susceptibility. J Clin Oncol 1994, 12(4):843-850.

51. Hopwood P, Shenton A, Lalloo F, Evans DG, Howell A: Risk perception and cancer worry: an exploratory study of the impact of genetic risk counselling in women with a family history of breast cancer. Journal of medical genetics 2001, 38(2):139..

52. van Campen C, Sixma HJ, Kerssens JJ, Peters L, Rasker JJ: Assessing patients' priorities and perceptions of the quality of health care: the development of the QUOTE-Rheumatic-Patients instrument. British journal of rheumatology 1998, 37(4):362-368.

53. Bottomley A, Aaronson NK: International perspective on health-related quality-of-life research in cancer clinical trials: the European Organisation for Research and Treatment of Cancer experience. J Clin Oncol 2007, 25(32):5082-5086.

54. Luo N, Fones CS, Lim SE, Xie F, Thumboo J, Li SC: The European Organization for Research and Treatment of Cancer Quality of Life Questionnaire (EORTC QLQ-c30): validation of English version in Singapore. Qual Life Res 2005, 14(4):1181-1186.

55. Sprangers MA, Cull A, Bjordal K, Groenvold M, Aaronson NK: The European Organization for Research and Treatment of Cancer. Approach to quality of life assessment: guidelines for developing questionnaire modules. EORTC Study Group on Quality of Life. Qual Life Res 1993, 2(4):287-295

56. Sprangers MA, Groenvold M, Arraras Jl, Franklin J, te Velde A, Muller M, Franzini L, Williams A, de Haes HC, Hopwood P, Cull A, Aaronson NK: The European Organization for Research and Treatment of Cancer breast cancer-specific quality-of-life questionnaire module: first results from a three-country field study. J Clin Oncol 1996, 14(10):2756-2768.

57. Horn EK, van Benthem TB, Hakkaart-van Roijen L, van Marwijk HW, Beekman AT, Rutten FF, van der Feltz-Cornelis CM: Cost-effectiveness of collaborative care for chronically ill patients with comorbid depressive disorder in the general hospital setting, a randomised controlled trial. BMC health services research 2007, 7:28.

58. Gielissen MF, Verhagen S, Witjes F, Bleijenberg G: Effects of cognitive behavior therapy in severely fatigued disease-free cancer patients compared with patients waiting for cognitive behavior therapy: a randomized controlled trial. J Clin Oncol 2006, 24(30):4882-4887.

59. Kessels RP: Patients' memory for medical information. Journal of the Royal Society of Medicine 2003, 96(5):219-222.

\section{Pre-publication history}

The pre-publication history for this paper can be accessed here: http://www.biomedcentral.com/1472-6874/11/39/prepub

doi:10.1186/1472-6874-11-39

Cite this article as: Visser et al:: Group medical visits in the follow-up of women with a BRCA mutation: design of a randomized controlled trial. BMC Women's Health 2011 11:39.

\section{Submit your next manuscript to BioMed Central and take full advantage of:}

- Convenient online submission

- Thorough peer review

- No space constraints or color figure charges

- Immediate publication on acceptance

- Inclusion in PubMed, CAS, Scopus and Google Scholar

- Research which is freely available for redistribution

Submit your manuscript at www.biomedcentral.com/submit 